\title{
Sustainability Challenges in Hydraulic Engineering for Agriculture
}

\author{
Perez-Sánchez M and López-Jiménez PA* \\ Hydraulic and Environmental Engineering Department, Universitat Politècnica de València, Spain
}

Submission: September 01, 2017; Published: September 08, 2017

"Corresponding author: López-Jiménez PA, Hydraulic and Environmental Engineering Department, Universitat Politècnica de València, Valencia, 46022 Spain, Tel: +3496387700; Email: mopesan1@upv.es; palopez@upv.es

\section{Opinion}

Nowadays, hydraulic engineering represents a compromise between science and technique that should go in parallel with the developmentof the farmer's performance, in agricultural terms. On the one hand, it is the science of water in movement, and its interactions with the surrounding environment, considered as a fluid. On the other hand, water management implications are a junction of challenges to be solved in order to provide the better solutions for population and environment in a sustainable framework.

Therefore, the current agriculture has two main criteria that must achieve obligatorily to reach, on the one side, the necessary production of the food to supply the populations, and the other side, the getting of these foods by techniques and habits that must be sustainable with the environment. Related to the water, the engineering solutions are called to optimize water management challenges, playing a significant role in many areas of human life: accessing to drinking water and sanitation, providing water for irrigation, offering protection against floods, allowing energy generation, among others. Water is essential for any sort of human activity as well as flora and fauna. The pressure to increase the food production is causing the difficulty to get the water resource with enough quantity and quality by the human consumption, as well as the use in farmers (e.g., crops, ranching, and aquaculture, among others)

Integral water management is a challenge itself as it represents a balance between population, industry and agricultural uses. When the consumed volume is observed, the importance of this resource is shown. Globally, the consumed water volume is $3925 \mathrm{~km}^{3} /$ year according to FAO [1], of which $69.53 \%$ is used by irrigation, $18.70 \%$ is used by industry and $11.77 \%$ by drinking water supply. Particularly, in Spain, the water consumed by the agricultural sector is above $80 \%(15 \%$ to urban supply and $5 \%$ to industry), being the volume of water used by agriculture $16344 \mathrm{hm}^{3} /$ year [2]
Therefore, if these values are considered, the irrigation represents very important water consumption. About 324 million hectares in the world are equipped for irrigation $(86 \%$ surface irrigation, $11 \%$ sprinkler irrigation and 3\% localized irrigation), representing $20 \%$ of the total area of cultivation [1]. The fact of carrying out the modernization involves also many energy implications. In general, the irrigation modernization (particularly in the Mediterranean zone) has reduced water consumption per area since 2000, when the irrigated national plans started. This modernization increased the hydraulic efficiency, but it has led to an increase of energy consumption. Likewise, sustainability in irrigation necessary involves energy and water nexus, and it must be achieved by using strategies that do not increase the overall carbon footprint. This development of strategies has to be univocally linked to new technologies [3], and the irrigation systems are not an exception. In 2014, around $4 \%$ of global electricity consumption was used to extract, distribute and treat water and wastewater, along with 50 million tons of equivalent oil from thermal energy, mainly diesel used for irrigation and gas pumps for desalination plants [2].

The decrease of the effects of climate change (along with other degradation of natural environment) is some of the challenges for the hydraulic engineers. These must be aimed to reduce the exploitation of natural resources (e.g., increasing water efficiency) and the impact on the environment (e.g., improving the fertirrigationapplication to reduce the pollution of the soil and/or air) such as: the ecological, water and energy footprints. In this sense, various regulations or agreements have been issued in relation to waterand energy, such as the Water Framework Directive. In this European legislation, the need to put less pressure on water resources and reducing diffuse pollution is explicitly indicated. Another example is the Kyoto Protocol, referring the need to improve efficiency and increasing use of renewable energy in any water uses [4]. 
Some actions can be performed to achieve the sustainability challenges in irrigation systems in terms of hydraulic engineering, among others:

a. The cost recovery principle (indicated by the Water Framework Directive) must be applied to encourage users to save water (as a resource) and increase efficiency (diminishing energy consumptions). Particularly in agricultural issues, poorest users should be subsided, while motivating water saving practices [5]. This can be reached by rewarding the production obtained per meter cubic of water used, instead of distributing the subsidies without taking into account production. It must be ensured that all the money users pay is invested by maintaining and improving these services.

b. The water managers must articulate the necessary tools, that are strongly liked to science development, to increase the energy and hydraulic efficiency (e.g., installation of microhydropower in water distribution networks [6])

c. Old or inefficient infrastructures must be renewed. This will reduce water leaks and so reduce energy and water consumption.

d. Farmers must be educated to be concerned for environmental issues and knowledge must be increased by incentivizing research in universities or institutions.

e. Decisions should be taken to favor reusing water and avoiding its discharge in streams, once the water has been purified as occurs currently, in which, a high percentage of purified water are not used to irrigation because the necessary infrastructures to connect water treatment plant and irrigation areas are not actually developed.

Therefore, the water resources management is currently called to be at the center of sustainable development, and this management cannot operate independently of the rest of inputs, which are focused on increasing the food production in the world. Consequently, it must grow on a sustainable basis. Sustainability is an integral concept and thus difficult to quantify, but it is important to be transmitted to lawyers, managers and farmers, in order to introduce this philosophy in society as a whole.

\section{References}

1. FAO, «Aquastat» (2017)

2. Seoane P, Allué R, Postigo MJ, Cordón MA (2013) Boletín Mensual de Estadística; Instituto Nacional de Estadística: Madrid, Spain.

3. Fekete B, Bogardi J (2015) Role of engineering in sustainable water management. Earth Perspectives Transdisciplinarity Enabled 2: 2.

4. Romero L, Perez-Sánchez M, López-Jiménez PA (2017) Environmental and energy problematic in the Mediterranean irrigation regions framework. IJEE 8(1): 51-62

5. García Molla M, Ortega Reig MV, Sanchis Ibor C, Avella Reus LF (2014). The effects of irrigation modernization on the cost recovery of water in the Valencia Region (Spain). Water Science and Technology: Water Supply 4(3): 414-420.

6. Pérez-Sánchez M, Sánchez-Romero FJ, Ramos HM, López Jiménez PA (2017) Energy Recovery in Existing Water Networks: Towards Greater Sustainability. Water 2(9): 97-117.

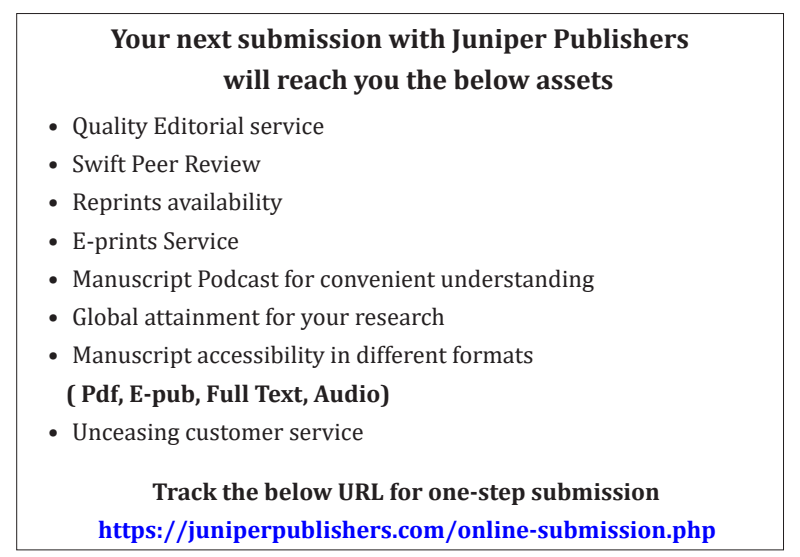

